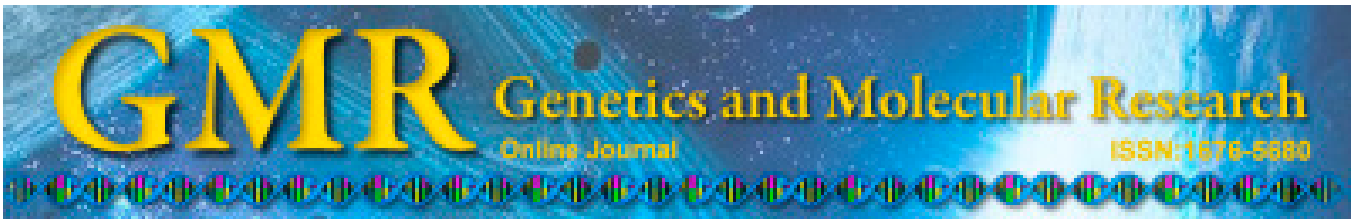

\title{
Variation of plasma levels of endothelin, calcitonin gene-related peptide, nitric oxide, and malondialdehyde in acute myocardial ischemia reperfusion injury in a rabbit model
}

\author{
${ }^{1}$ Department of Cardiovascular Surgery, \\ Corresponding author: G.X. Feng \\ E-mail: fenggxing@126.com \\ Genet. Mol. Res. 14 (2): 5577-5584 (2015) \\ Received July 25, 2014 \\ Accepted December 4, 2014 \\ Published May 25, 2015 \\ DOI http://dx.doi.org/10.4238/2015.May.25.9
}

Y.B. Zhao' ${ }^{1}$, Y.Z. Wang ${ }^{2}$, Y.H. Yue ${ }^{3}$, W.C. Zhao ${ }^{1}$ and G.X. Feng ${ }^{1}$ Fourth Hospital of Hebei Medical University, Shijiazhuang, China ${ }^{2}$ Department of Cardiac Surgery, Hebei General Hospital, Shijiazhuang, China ${ }^{3}$ Department of Neurology, Hebei General Hospital, Shijiazhuang, China

\begin{abstract}
We examined the variation in plasma levels of endothelin (ET), calcitonin gene-related peptide (CGRP), nitric oxide (NO), and malondialdehyde (MDA), as well as superoxide dismutase (SOD) activity, in acute myocardial ischemia reperfusion injury in a rabbit model. Seventy rabbits were randomly assigned into 3 groups. Openchest surgery (OCS) was performed for all rabbits. Group A $(\mathrm{N}=20)$ received sham-surgery, group $\mathrm{B}(\mathrm{N}=25)$ was the reperfusion group, and group $\mathrm{C}(\mathrm{N}=25)$ was the infarction group. At $12 \mathrm{~h}$ after chest closure, plasma ET levels in groups B and C were clearly increased, while CGRP levels were clearly decreased, particularly in group B. At $24 \mathrm{~h}$ after chest closure, ET levels were higher than before OCS, while there was no significant difference between groups B and C. ET in group B was decreased, while that in group $C$ was increased at $12 \mathrm{~h}$. No significant difference in CGRP was observed between 12 and $24 \mathrm{~h}$ after chest
\end{abstract}


closure. NO levels in groups B and $\mathrm{C}$ at $12 \mathrm{~h}$ after chest closure were significantly decreased compared to those before OCS. NO levels in group B at 24, 48, and $72 \mathrm{~h}$ were significantly lower than those at $12 \mathrm{~h}$, while those of group $\mathrm{C}$ were not significantly changed after $12 \mathrm{~h}$. Dynamic monitoring and comparison of plasma levels of ET, CGRP, NO, and MDA as well as SOD activity revealed that appropriate intervention of these factors may reduce reperfusion injury.

Key words: Myocardial ischemia; Reperfusion injury

\section{INTRODUCTION}

With the development and promotion of a variety of revascularization methods such as thrombolytic therapy, percutaneous transluminal coronary angioplasty, and coronary bypass surgery, improvement in clinical outcome is achieved through blood supply recovery to the ischemic myocardium and reduced cell damage.

Endothelin (ET) was first isolated and purified by Yanagisawa from the supernatant of endothelial cells from swine aorta. ET exists in all vascular tissues of the central system and peripheral system, and it is most abundant in the cardiovascular system, showing a strong vasoconstriction effect (Berlex and Cedar, 1991). Plasma ET level may be used as a reference index for the diagnosis and determining the prognosis of myocardial infarction (Stewart et al., 1991; Tang and Tang, 1993). Many scholars found that after acute myocardial ischemia, endogenous ET is increasingly released in systemic circulation and coronary circulation, mainly in an autocrine/paracrine manner by endothelial cells. Calcitonin gene-related peptide (CGRP) is a bioactive peptide containing 37 amino acid residues derived from the alternative splicing of the calcitonin gene. It is widely distributed in the nervous and cardiovascular systems, and it has a strong vasodilator effect and positive inotropic and chronotropic effects on the heart. The antagonistic effect of CGRP on vasoconstrictor action of ET was determined previously, and infusion of CGRP can significantly reduce plasma ET level (Keith et al., 2000). Therefore, under normal circumstances, the 2 factors influence each other, and mutual interaction and restraint of these factors maintain cardiovascular physiological function.

In this study, we examined variations in plasma levels of ET, CGRP, nitric oxide (NO), and malondialdehyde (MDA) as well as superoxide dismutase (SOD) activity in acute myocardial ischemia reperfusion injury in a rabbit model. We explored the roles and relationships of these molecules in myocardial ischemia reperfusion injury to provide a theoretical basis for clinical treatment. In addition, a casting mold of coronary arteries was prepared using a casting agent solution, a mixture of acrylonitrile butadiene styrene (ABS) resin and acetone, for morphological study.

\section{MATERIAL AND METHODS}

Seventy rabbits, 35 males and 35 females, aged 7-9 weeks and weighing about 2.0 $\mathrm{kg}$, were provided by the experiment center of Hebei Medical University. All rabbits were randomly assigned into group $A(N=20)$, group $B(N=25)$, and group $C(N=25)$.

Open-chest surgery (OCS) was performed for all rabbits and a string was placed around the coronary artery at the initial segment of the anterior descending branch (Figures 1 and 2). Group 
A was the sham-surgery group, and the anterior descending branch was not ligated and the chest was closed $6 \mathrm{~h}$ after OCS. Group B was the reperfusion group, and the anterior descending branch was ligated and recanalized $6 \mathrm{~h}$ later, and then the chest was closed. Group $\mathrm{C}$ was the infarction group, the anterior descending branch was ligated, and the chest was closed $6 \mathrm{~h}$ after OCS.

During the procedure, $1 \mathrm{mg} / \mathrm{kg}$ heparin sodium was applied after OCS to prevent thrombosis after coronary artery occlusion. For all rabbits, $5 \mathrm{~mL}$ venous blood was collected before OCS and at 12, 24, 48, and $72 \mathrm{~h}$ after chest closure. The blood sample was mixed with $75 \mu \mathrm{L} 7.5 \%$ ethylenediaminetetraacetic acid and $100 \mu \mathrm{L}$ aprotinin, and plasma was obtained by centrifugation at $1600 \mathrm{~g}$ at $4^{\circ} \mathrm{C}$ for $10 \mathrm{~min}$ and stored at $-80^{\circ} \mathrm{C}$ until use.

To prepare the casting agent solution, $\mathrm{ABS}$ resin was mixed with acetone at a ratio of 1:20 ( $1 \mathrm{~g}$ resin mixed with $20 \mathrm{~mL}$ acetone). At the end of the experiment, all rabbits were sacrificed, and the casting agent solution was injected from the coronary orifice to prepare the casting mold of coronary arteries. Corrosion of the cardiac muscle was achieved using $37 \%$ hydrochloric acid, and recanalization of the blood vessel was examined.

Plasma levels of ET and CGRP were detected by radioimmunoassay using ET and CGRP kits purchased from Beijing Purevalley Biotech Co., Ltd. (Beijing, China). The plasma levels of NO and MDA as well as SOD activity were detected using a colorimetric method and NO, SOD, and MDA kits provided by the Nanjing Jiancheng Bioengineering Institute (Jiangsu, China).

All data are reported as means \pm standard deviation. One-way analysis of variance was applied to compare groups. A P value of $<0.05$ was considered to be statistically significant.

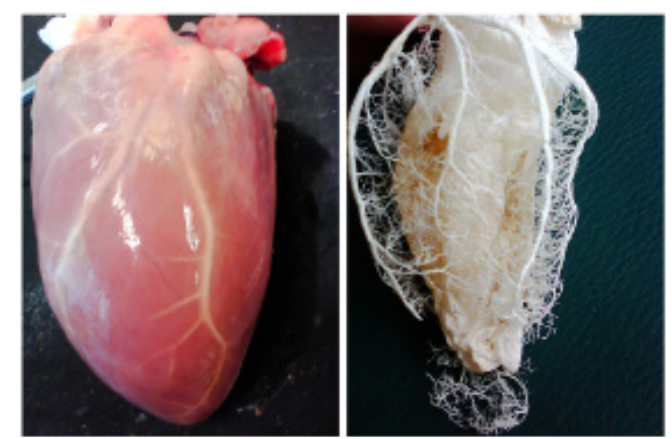

Figure 1. Animal heart after casting agent solution injection, and casting mold of the coronary artery after cardiac muscle melting.

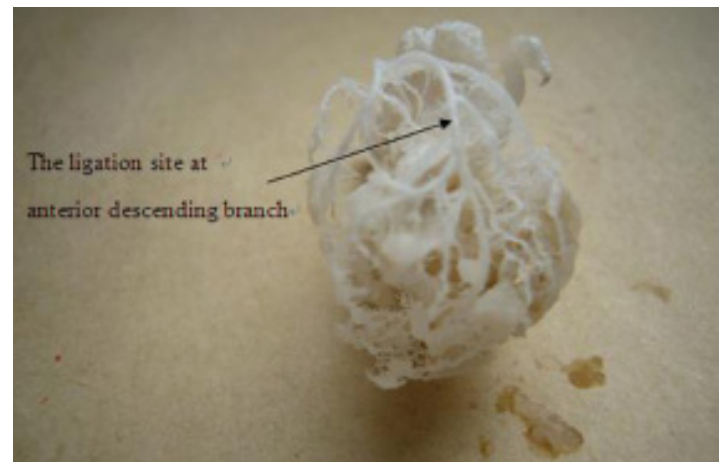

Figure 2. Molding of the coronary artery of rabbit. 


\section{RESULTS}

\section{Casting mold of coronary arteries}

In group B, the middle and lower segments of the anterior descending branch were missing in the casting mold from 1 rabbit, which may have been due to thrombosis at the ligation site; thus, data from this rabbit were excluded from analysis. In group $\mathrm{C}$, the middle and lower segments of the anterior descending branch remained as a thin vessel in the casting mold from 1 rabbit, which may have occurred because the coronary artery was not completely occluded after ligation; data from this rabbit were also excluded from analysis.

\section{Variation in plasma ET levels}

As shown in Table 1, in group A, there was no significant difference in plasma ET level at different time points $(\mathrm{P}>0.05)$. In group B, plasma ET levels at $12,24,48$, and $72 \mathrm{~h}$ after chest closure were significantly higher than those before OCS $(\mathrm{P}<0.05)$, and plasma ET levels at 24, 48, and $72 \mathrm{~h}$ were significantly lower than those at $12 \mathrm{~h}(\mathrm{P}<0.05)$. In group C, plasma ET levels at 12, 24, 48, and $72 \mathrm{~h}$ after chest closure were significantly higher than before OCS $(\mathrm{P}<0.05)$, and plasma ET level was not decreased until $72 \mathrm{~h}$ after chest closure.

Before OCS, plasma ET levels were not significantly different among groups. At 12, 24,48 , and $72 \mathrm{~h}$ after chest closure, plasma ET levels in groups B and C were significantly higher than those in group A $(\mathrm{P}<0.05)$. Plasma ET level in group B was significantly higher than that in group $\mathrm{C}$ at $12 \mathrm{~h}$ after chest closure $(\mathrm{P}<0.05)$, while there was no significant difference between groups $\mathrm{B}$ and $\mathrm{C}$ at $24 \mathrm{~h}$ after chest closure $(\mathrm{P}>0.05)$, and the plasma ET levels in group $\mathrm{C}$ were significantly higher than those in group $\mathrm{B}$ at 48 and $72 \mathrm{~h}$ after chest closure $(\mathrm{P}<0.05)$.

\begin{tabular}{|c|c|c|c|c|c|c|}
\hline & Group & $\mathrm{T} 1$ & $\mathrm{~T} 2$ & $\mathrm{~T} 3$ & $\mathrm{~T} 4$ & $\mathrm{~T} 5$ \\
\hline \multirow[t]{3}{*}{$\mathrm{ET}(\mathrm{pg} / \mathrm{mL})$} & $\mathrm{A}$ & $63.15 \pm 20.50$ & $67.70 \pm 19.30$ & $65.00 \pm 18.99$ & $64.45 \pm 16.20$ & $63.98 \pm 17.57$ \\
\hline & B & $63.00 \pm 21.01$ & $108.11 \pm 12.75^{* \#}$ & $95.09 \pm 13.14^{* \#}$ & $93.67 \pm 10.56^{* \#}$ & $90.58 \pm 17.55^{\text {*\# }}$ \\
\hline & $\mathrm{C}$ & $62.89 \pm 19.88$ & $85.79 \pm 13.76^{* \# \$}$ & $99.50 \pm 12.47 * \#$ & $107.65 \pm 13.00^{* \# \$}$ & $106.32 \pm 10.86^{* \# \$}$ \\
\hline \multirow[t]{3}{*}{ CGRP (pg/mL) } & $\mathrm{A}$ & $51.41 \pm 8.65$ & $52.77 \pm 9.56$ & $53.62 \pm 10.37$ & $53.27 \pm 11.60$ & $50.98 \pm 11.45$ \\
\hline & $\mathrm{B}$ & $50.98 \pm 9.01$ & $37.90 \pm 7.30^{* \#}$ & $39.34 \pm 8.10^{* \#}$ & $45.34 \pm 8.46^{* \#}$ & $46.88 \pm 7.64$ \\
\hline & $\mathrm{C}$ & $52.22 \pm 9.23$ & $44.02 \pm 8.67 * \# \$$ & $42.55 \pm 7.37$ *\# & $46.79 \pm 8.06^{* \#}$ & $48.97 \pm 8.74$ \\
\hline \multirow[t]{3}{*}{$\mathrm{NO}(\mu \mathrm{M})$} & A & $71.50 \pm 12.99$ & $72.90 \pm 13.32$ & $73.01 \pm 11.89$ & $70.98 \pm 10.67$ & $74.02 \pm 12.35$ \\
\hline & B & $70.21 \pm 11.23$ & $33.72 \pm 9.01$ *\# & $24.42 \pm 8.58^{* \#}$ & $23.54 \pm 9.32$ *\# & $21.68 \pm 8.74^{* \#}$ \\
\hline & $\mathrm{C}$ & $69.86 \pm 10.78$ & $34.34 \pm 10.51$ *\# & $36.76 \pm 8.94 * \#$ & $37.84 \pm 10.36 * \#$ & $35.46 \pm 9.72 * \#$ \\
\hline \multirow[t]{3}{*}{ SOD (U/mg prot) } & $\mathrm{A}$ & $180.21 \pm 7.10$ & $174.91 \pm 7.00$ & $175.89 \pm 6.72$ & $178.37 \pm 7.90$ & $182.74 \pm 8.69$ \\
\hline & B & $178.34 \pm 8.26$ & $136.74 \pm 6.75^{* \#}$ & $127 \pm 9.23^{* \#}$ & $120.33 \pm 10.14^{* \#}$ & $117.56 \pm 9.88^{* \#}$ \\
\hline & $\mathrm{C}$ & $178.03 \pm 7.98$ & $156.67 \pm 9.34 * \# \$$ & $140.78 \pm 10.02^{* \# \$}$ & $135.47 \pm 9.78^{* \# \$}$ & $144.87 \pm 10.35^{* \# \$}$ \\
\hline \multirow[t]{3}{*}{$\operatorname{MDA}(\mu \mathrm{M})$} & A & $7.54 \pm 0.70$ & $7.50 \pm 0.65$ & $8.58 \pm 0.60$ & $7.69 \pm 0.82$ & $8.32 \pm 0.58$ \\
\hline & $\mathrm{B}$ & $7.48 \pm 0.82$ & $14.67 \pm 0.89^{* \#}$ & $18.96 \pm 0.94 * \#$ & $23.67 \pm 0.68^{* \#}$ & $19.77 \pm 0.74^{* \#}$ \\
\hline & $\mathrm{C}$ & $7.50 \pm 0.88$ & $10.89 \pm 0.78^{* \# \$}$ & $17.69 \pm 0.60^{* \# \mathrm{~S}}$ & $16.87 \pm 0.78^{* \# \mathrm{~S}}$ & $14.89 \pm 0.83^{* \# \mathrm{~S}}$ \\
\hline
\end{tabular}

*P $<0.05$ when compared with $\mathrm{T} 1 ;{ }^{\#} \mathrm{P}<0.05$ when compared with group $\mathrm{A} ;{ }^{\mathrm{S}} \mathrm{P}<0.05$ when compared with group B. ET, endothelin; CGRP, calcitonin gene-related peptide; NO, nitric oxide; SOD, superoxide dismutase; MDA, malondialdehyde. 


\section{Variation in plasma CGRP levels}

In group A, there was no significant difference in plasma CGRP level at the different time points (Table $1 ; \mathrm{P}>0.05$ ). In groups $\mathrm{B}$ and $\mathrm{C}$, plasma CGRP levels at 12, 24, and $48 \mathrm{~h}$ after chest closure were significantly lower than those before OCS $(\mathrm{P}<0.05)$, and plasma CGRP level at $72 \mathrm{~h}$ was not significantly lower than that before OCS $(\mathrm{P}>0.05)$.

Before OCS and at $72 \mathrm{~h}$ after chest closure, plasma CGRP levels were not significantly different among groups $(\mathrm{P}>0.05)$. At $12 \mathrm{~h}$ after chest closure, plasma CGRP levels in groups $\mathrm{B}$ and $\mathrm{C}$ were significantly lower than that in group $\mathrm{A}(\mathrm{P}<0.05)$, and plasma CGRP level in group B was significantly lower than that in group $\mathrm{C}(\mathrm{P}<0.05)$. At 24 and $48 \mathrm{~h}$ after chest closure, plasma CGRP levels in groups $\mathrm{B}$ and $\mathrm{C}$ were significantly lower than that in group $\mathrm{A}(\mathrm{P}<0.05)$, and there was no significant difference in plasma CGRP levels between groups $\mathrm{B}$ and $\mathrm{C}(\mathrm{P}>0.05)$.

\section{Variation in plasma NO levels}

As shown in Table 1, in group A, there was no significant difference in plasma NO levels at different time points $(\mathrm{P}>0.05)$. In group $\mathrm{B}$, plasma NO levels at 12, 24, 48 and $72 \mathrm{~h}$ after chest closure were all significantly lower than those before OCS $(\mathrm{P}<0.05)$; plasma NO level at $24 \mathrm{~h}$ was significantly lower than that at $12 \mathrm{~h}$, and there was no significant difference in plasma NO levels at 24, 48, and $72 \mathrm{~h}(\mathrm{P}>0.05)$. In group $\mathrm{C}$, plasma NO levels at 12, 24, 48 , and $72 \mathrm{~h}$ after chest closure were significantly lower than those before OCS $(\mathrm{P}<0.05)$, and there was no significant difference in plasma NO levels at 12, 24, 48, and $72 \mathrm{~h}(\mathrm{P}>0.05)$.

Before OCS, plasma NO levels were not significantly different among groups $(\mathrm{P}>$ $0.05)$. At $12,24,48$, and $72 \mathrm{~h}$ after chest closure, plasma NO levels in groups $\mathrm{B}$ and $\mathrm{C}$ were significantly lower than those in group A $(\mathrm{P}<0.05)$. At $12 \mathrm{~h}$ after chest closure, there was no significant difference in plasma NO levels between groups B and C $(\mathrm{P}>0.05)$. At 24,48 , and $72 \mathrm{~h}$ after chest closure, plasma NO levels in group B were significantly lower than those in group $\mathrm{C}(\mathrm{P}<0.05)$.

\section{Variation in SOD activity}

In group A, there was no significant difference in SOD activity at different time points (Table $1 ; \mathrm{P}>0.05$ ). In groups B and $\mathrm{C}$, SOD activity at $12,24,48$, and $72 \mathrm{~h}$ after chest closure was significantly lower than that before OCS $(\mathrm{P}<0.05)$.

Before OCS, there was no significant difference in SOD activity among groups. At 12, 24,48 , and $72 \mathrm{~h}$ after chest closure, SOD activity in groups B and C was significantly lower than that in group A $(\mathrm{P}<0.05)$, and SOD activity in group B was significantly lower than that in group $\mathrm{C}$.

\section{Variation in plasma MDA levels}

As shown in the Table 1, in group A, there was no significant difference in plasma MDA levels at the different time points ( $\mathrm{P}>0.05)$. In group B, plasma MDA levels at 12, 24, 48 , and $72 \mathrm{~h}$ after chest closure were significantly higher than those before OCS $(\mathrm{P}<0.05)$, and plasma MDA level at $72 \mathrm{~h}$ was significantly lower than that at $48 \mathrm{~h}(\mathrm{P}<0.05)$. In group $\mathrm{C}$, 
plasma MDA levels at 12, 24, 48, and $72 \mathrm{~h}$ after chest closure were significantly higher than those before OCS $(\mathrm{P}<0.05)$, and plasma MDA level was decreased after $24 \mathrm{~h}$ and the level at $72 \mathrm{~h}$ was significantly lower than that at $48 \mathrm{~h}$.

Before OCS, plasma MDA levels were not significantly different among groups. At $12,24,48$, and $72 \mathrm{~h}$ after chest closure, plasma MDA levels in groups B and C were significantly higher than those in group A $(\mathrm{P}<0.05)$, and plasma MDA levels in group B were significantly higher than those in group $\mathrm{C}$.

\section{DISCUSSION}

In this study, variations in the plasma levels of ET, CGRP, NO, and MDA as well as SOD activity during myocardial ischemia reperfusion injury were examined in a rabbit model, and the correlations among these factors during myocardial ischemia reperfusion injury were explored.

We found that at $12 \mathrm{~h}$ after chest closure, plasma ET levels in groups B and C were clearly increased, while CGRP levels were clearly decreased; the change was more obvious in group B (ischemic reperfusion group). At $24 \mathrm{~h}$ after chest closure, ET levels were still clearly higher than before OCS, while there was no significant difference between groups B and C; compared to at $12 \mathrm{~h}$, the ET level in group B was decreased while that in group C was increased. For CGRP, there was no significant difference between 12 and $24 \mathrm{~h}$ after chest closure. These results suggest that ET and CGRP are involved in the pathogenesis of myocardial ischemia reperfusion injury. Various factors and metabolites produced during the early phase of myocardial ischemia-reperfusion may have stimulating effects on endothelial cells and thus increase the synthesis and release of ET. CGRP level was also increased. However, because of the rapid degradation of CGRP and large increase in ET, CGRP decreased rapidly at $12 \mathrm{~h}$ after chest closure, and thus the balance between the 2 factors was interrupted. The increase in ET and decrease in CGRP lead to further contraction of the peripheral vascular system, thus aggravating myocardial ischemia and hypoxia. Thus, ET and CGRP are involved in myocardial ischemia reperfusion injury. After the acute phase of reperfusion, the release of secondary induced ET may be gradually decreased, and the consumption of CGRP in ET antagonism is also reduced, resulting in decreased plasma ET levels in group B at $24 \mathrm{~h}$ (compared with $12 \mathrm{~h}$ ) and gradually increasing CGRP levels (returned to preoperative level at $72 \mathrm{~h}$ ).

NO is an important messenger and effector molecule, which is involved in many physiological and pathological processes such as the regulation of vascular tension, neurotransmission, inflammation, and immune response (Zhong and Sun, 1997). NO is formed by the coronary endothelium in the heart. Apoptosis is the characteristic pathophysiology of myocardial ischemia reperfusion injury, which is an important process during the pathogenesis of myocardial damage and heart failure (Wu, 2005; Ramsay et al., 2005). Recent studies have confirmed the relationship between $\mathrm{NO}$ and cell apoptosis in myocardial ischemia reperfusion injury (Weiland et al., 1991; Stefanelli et al., 1999; Pinsky et al., 1999). This indicates that $\mathrm{NO}$ can both reduce and mediate reperfusion injury. The protective role of NO in ischemia reperfusion injury is thought to be related to the anti-peroxidation effect (Wink et al., 1993) and resistance towards neutrophil adhesion and aggregation (Pabla et al., 1996). NO-mediated myocardial injury may be primarily related to peroxynitrite anion (Wang and Zweier, 1996), 
during which an excess of $\mathrm{NO}$ reacts rapidly with oxygen to generate large amounts of oxygen free radicals, such as peroxynitrite, which can further react to form $\mathrm{HO}^{-}, \mathrm{NO}^{-2}$, and $\mathrm{NO}^{-3}$. This may lead to myocardial ischemia reperfusion injury and aggravate the condition (Matheis et al., 1992). Recently, it was revealed that ET and NO are mutually antagonistic vasoactive substances. Under physiological conditions, the dynamic balance between the 2 factors maintains normal coronary diastolic function and thus ensures a normal blood supply to the cardiac muscle. Under the pathological state, the balance is broken, showing decreased synthesis or release of NO and increased synthesis and secretion of ET, leading to coronary artery spasm and thus stopping blood flow (Brunner, 1997). The results of this study showed that NO levels in groups $\mathrm{B}$ and $\mathrm{C}$ at $12 \mathrm{~h}$ after chest closure were significantly decreased compared to those before OCS, and NO levels in group B at 24, 48, and $72 \mathrm{~h}$ were significantly lower than those at $12 \mathrm{~h}$, while those in group $\mathrm{C}$ were not significantly changed after $12 \mathrm{~h}$. Accompanied by variations in ET levels, our results show that ET and NO are mutually antagonistic vasoactive substances. After myocardial ischemia reperfusion, sustained reduction of NO may result from endothelial dysfunction, indicating that nitric oxide supplement is also a good clinical choice.

Large amounts of oxygen free radicals generated after myocardial ischemia may cause serious myocardial injury. Oxygen free radicals are a class of highly active substances that can oxidize unsaturated fatty acids on the cell membrane to form MDA (Ruiz-Ginés et al., 2000). Therefore, MDA levels may reflect the degree of lipid peroxidation indirectly and thereby reflect the content of oxygen free radicals. SOD can remove oxygen free radicals and thus compete with MDA to protect the cardiovascular system. SOD activity is positively correlated with its anion clearance and antioxidant capacity as well as a protective effect. Lower SOD activity results in higher consumption because of the higher oxygen free radical content, resulting in a weakened cardiovascular protective effect. Our results showed that in group B, SOD activity at $12,24,48$, and $72 \mathrm{~h}$ was significantly decreased compared with that before OCS, showing a decreasing trend, while MDA levels after chest closure were significantly increased compared with those before OCS. In addition, the change was more obvious in group $\mathrm{B}$ than in group $\mathrm{C}$ at each time point. These results indicate that during the early phase of ischemia reperfusion injury, SOD and MDA were involved in the pathogenesis.

The mixture of ABS resin and acetone is an ideal casting agent solution for preparing casting molds of small blood vessels, which can provide morphological evidence of clinical in experimental research.

The dynamic monitoring and comparison of plasma levels of ET, CGRP, NO, and MDA as well as SOD activity in each group revealed that these factors are involved in pathogenesis during the early phase of reperfusion injury, and thus appropriate intervention of these factors may reduce reperfusion injury. However, the exact mechanism requires further examination.

Previous studies demonstrated mutual antagonism between ET and CGRP in ischemia reperfusion injury. Our results showed that $12 \mathrm{~h}$ after myocardial ischemia, plasma ET level increased sharply, while CGRP level decreased. Various factors and metabolites produced during the early phase may have a stimulating effect on endothelial cells, increasing the synthesis and release of ET and leading to the consumption of CGRP and the decreased CGRP levels.

ET and NO are mutually antagonistic vasoactive substances. Based on our results, it can be inferred that NO mediates reperfusion injury, while also reducing reperfusion injury through its antagonism effect on ET. However, this requires further investigation. 


\title{
Conflicts of interest
}

\author{
The authors declare no conflict of interest.
}

\section{References}

Berlex L and Cedar K (1991). Endothlins. FASEB J. 5: 2713-2720.

Brunner F (1997). Interaction of nitric oxide and endothelin-1 in ischemia/reperfusion injury of rat heart. J. Mol. Cell Cardiol. 29: 2363-2374.

Keith IM, Tjen-A-Looi S, Kraiczi H and Ekman R (2000). Three-week neonatal hypoxia reduces blood CGRP and cause persistent pulmonary hypertension in rats. Am. J. Physiol. Heart Circ. Physiol. 279: 1571-1578.

Matheis G, Sherman MP, Buckberg GD, Haybron DM, et al. (1992). Role of L-arginine-nitric oxide pathway in myocardial reoxygenation injury. Am. J. Physiol. 262: 16-20.

Pabla R, Buda AJ, Flynn DM, Blessé SA, et al. (1996). Nitric oxide attenuates neutrophil-mediated myocardial contractile dysfunction after ischemia and reperfusion. Circ. Res. 78: 65-72.

Pinsky DJ, Aji W, Szabolcs M, Athan ES, et al. (1999). Nitric oxide triggers programmed cell death (apoptosis) of adult rat ventricular myocytes in culture. Am. J. Physiol. 277: 1189-1199.

Ramsay J, Shernan S, Fitch J, Finnegan P, et al. (2005). Increased creatine kinase MB level predicts postoperative mortality after cardiac surgery independent of new Q waves. J. Thorac. Cardiovasc. Surg. 129: 300-306.

Ruiz-Ginés JA, López-Ongil S, González-Rubio M, González-Santiago L, et al. (2000). Reactive oxygen species induce proliferation of bovine aortic endothelial cells. J. Cardiovasc. Pharmacol. 35: 109-113.

Stefanelli C, Pignatti C, Tantini B, Stanic I, et al. (1999). Nitric oxide can function as a killer molecule or an antiapoptotic effector in cardiomyocytes. Biochim. Biophys. Acta 1450: 406-413.

Stewart DJ, Kubac G, Costello KB and Cernacek P (1991). Increased plasma endothelin-1 in the early hours of acute myocardial infarction. J. Am. Coll. Cardiol. 18: 38-43.

Tang J and Tang CS (1993). Endothelin and ischemic heart disease based on clinical research (1st edn.). Chinese Peking Union Medical College, Beijing Medical University Press, Beijing.

Wang P and Zweier JL (1996). Measurement of nitric oxide and peroxynitrite generation in the postischemic heart. Evidence for peroxynitrite-mediated reperfusion injury. J. Biol. Chem. 271: 29223-29230.

Weiland U, Haendeler J and Ih Ling C (1991). Inbeling of nuclear DNA fragmentation. J. Cell Biol. 119: 493-501.

Wink DA, Hanbauer I and Krishna MC (1993). Nitric oxide protects against cellular damage and cytotoxicity from reactive oxygen species. Proc. Natl. Acad. Sci. U S A 90: 9813-9817.

Wu AH (2005). Markers for early detection of cardiac diseases. Scand. J. Clin. Lab. Invest. Suppl. 240: 112-121.

Zhong CS and Sun AY (1999). Nitric oxide in Biomedicine. Shanghai Medical University Press, Shanghai. 